\title{
Disease due to echovirus type 19 in Birmingham, England, 1975: relationship to 'epidemic neuromyasthenia'
}

\author{
A. P. BALL \\ B.Sc., M.B., Ch.B., M.R.C.P.(U.K.). \\ Department of Communicable and Tropical Diseases, East Birmingham Hospital, Birmingham B9 5ST
}

\begin{abstract}
Summary
In the summer of 1975 an extensive epidemic of disease due to echovirus type 19 occurred in the West Midlands. The features of this outbreak, and their relationship to the syndrome referred to as 'epidemic neuromyasthenia', are discussed. The two diseases are considered to be separate entities.
\end{abstract}

\section{Introduction}

Before 1974, relatively few cases of disease due to echovirus type 19 (ECHO 19) were reported in Britain, but in that year an increasing number of isolations heralded an epidemic which was to last throughout the year and which would reappear in larger numbers in 1975. In 1974, 566 isolations of ECHO 19 were reported to the Director of the Public Health Laboratory Service (P.H.L.S.), the majority of which occurred in the North-East of England. From this area, Codd et al. (1976) reported an epidemic of disease in 1974 with clinical features varying from viraemic shock syndromes in infancy, upper respiratory tract and gastrointestinal infections, Bornholm disease and pyrexia of uncertain origin, to viral meningitis with typical cerebrospinal fluid changes. These authors noted that as the epidemic declined in the North-East, the disease became more widespread elsewhere and that isolations continued into the winter months. This latter phenomenon, unusual in disease due to enteroviruses, suggested to them that a recrudescence of the disease to epidemic proportions would occur in 1975. This view was shared by the editorial staff of the British Medical Journal (Leading Article, 1975) who, commenting on the continued isolations of ECHO 19 over the winter of 1974-1975, predicted a further series of epidemics in the following summer.

These predictions proved increasingly accurate, as over the spring and summer months of 1975 isolations rapidly increased to major proportions, over 1500 cases of disease due to ECHO 19 being reported to the P.H.L.S. in that year. The brunt of the epidemic fell on the West Midlands, and in particular the City of Birmingham and its environs.
The spectrum of disease seen in patients and their families during the Birmingham outbreak (Gould et al., 1977), and its relevance, or otherwise, to the continuing problem of identification of the entity of 'epidemic neuromyasthenia' previously referred to as benign myalgic encephalomyelitis or Royal Free disease, will now be discussed.

\section{The Birmingham outbreak}

Between January and September 1975, 290 patients from the Greater Birmingham area were admitted to East Birmingham Hospital (EBH) suffering from aseptic meningitis. The diagnosis was confirmed by the isolation of the virus (ECHO 19), or cerebrospinal fluid examination, or both. The CSF showed a predominantly lymphocytic pleocytosis in $86 \%$ of the patients. ECHO 19 virus was cultured in $204(70 \%)$ of the patients, and in 192 $(66 \%)$, including all of those with normal CSF at the time of examination, it was recovered from CSF. Although ECHO 19 was not isolated from all 290 patients, the prevalence of this virus in Birmingham during the outbreak makes it likely that the majority of 'culture negative' patients were infected with it. During the period of the epidemic, 2751 specimens from patients throughout Birmingham were examined by the Regional Virus Laboratory at EBH. Of these, $24 \%$ yielded ECHO 19 virus, whereas isolations of all other viruses amounted to only $4.5 \%$.

The epidemic began in January and February in the centre of the City, from whence it rapidly spread during the spring and early summer, to the North and East, particularly affecting Chelmsley Wood new town sited at the eastern border of Birmingham. The admission rate from Chelmsley Wood during the outbreak was $85 / 100000$ of the population compared with an average for Birmingham as a whole of $20 / 100000$.

When the size of the outbreak was appreciated, a prospective study of admissions to EBH was commenced, and a total of seventy-eight patients with confirmed ECHO 19 aseptic meningitis were 
studied. Of these, $56 \%$ were male and $44 \%$ were female. Peaks of incidence were noted in school age (5-15 years) children and in ferales in the third decade (mothers of young children).

Prodromal symptoms were reported by $65 \%$ of the seventy-eight patients. Pyrexia $(60 \%)$, upper respiratory tract symptoms $(52 \%)$, and myalgia of the Bcrnholm type, affecting principally the intercostal and abdominal musculature, $(40 \%)$ were predon inant. The prodromal phase merged, without rcspite, into the meningeal phase of the illness. Symptoms thereafter were headache $(100 \%)$, neck stiffness $(90 \%)$, photophobia $(82 \%)$, vomiting $(67 \%)$ and pyrexia $(53 \%)$. Most of the patients presented within 1-3 days of the onset of symptoms. Myalgia, when present, persisted over several days and in a number of patients was sufficiently severe as to mimic an 'acute abdomen'. Conjunctivitis occurred in $22 \%$ of patients and a faint maculopapular rash was present in $6 \%$.

No objective focal neurological signs were detccted in any of the patients but $44 \%$ complained of dizziness and unsteadiness on their feet and mental confusion or delirium was a feature in $13 \%$. In the latter patients, hyperpyrexia was not a feature, the mean temperature elevation being $38.2 \%$.

In almost all patients the total duration of the illness was less than 2 weeks and the majority were ambulant and convalescent 1 week after the onset of symptoms. There were no deaths associated with infections due to ECHO 19. Following the acute illness, approximately $10-15 \%$ of patients, predominantly young adult females who returned home to care for young families, complained of intermittent headache. This symptom lasted for periods of up to 3 months. One adult male was readmitted 1 week after discharge with severe headache but lumbar puncture produced normal CSF. An adult female patient complained for several months after discharge of muscular weakness and myalgia, headache and photophobia. No objective neurological features were elicited and repeat lumbar punctures, EEG, brain scan and lumbar air encephalogram were all normal. Her symptoms finally settled after her negative investigations.

Family contacts of twenty-five of the seventy-eight patients were requested to provide stool specimens to assess the prevalence of the virus in the patients' environment. A specimen was returned by ninetytwo of 102 family contacts and ECHO 19 virus was isolated from thirty-seven $(40 \%)$. These isolations came from eighteen of the twenty-five families. Twelve of the positive contacts admitted to malaise, and headaches (10), pyrexia (6), and vomiting (3), between 1 and 3 weeks before examination of their stools. Twenty-five positive contacts gave no history of discernible illness. It is of note that twenty-nin of the positive contacts were children aged 15 years. or less but this bias corresponded to the age distria bution of the families and did not indicate a highef? prevalence in this age group.

In mid-August of 1975 the numbers of neve isolations of ECHO 19 showed the beginning of a marked decline and by mid-September the epidemic was replaced by sporadic cases. At that time the prevalent virus became ECHO 30 which resulted ina number of small clusters of cases of disease before this virus, too, declined during the early winter months.

\section{Discussion \\ ECHO 19 disease and 'epidemic neuromyasthenia'}

The epidemic of disease due to ECHO 19 described above resulted in a large number of admissions tow hospital of patients with a fairly clear-cut syndrome of aseptic meningitis, from whom the virus was? isolated in a major proportion $(70 \%)$. Although the spectrum of disease described by Codd et al. (1976) was not observed in the admitted patients from Birmingham, close liaison with general practitioners during the outbreak revealed major morbidity in the general population. Their patients suffered illn issvarying from gastrointestinal upsets to myalgia $f$ the Bornholm type and, especially in the Chelms Wood area, it seems likely that much of this mor-o bidity was due to ECHO 19. Other hospitals in the City also admitted cases of disease due to ECHO 190 and the Children's Hospital saw a number of caseso of the viraemic type of presentation recorded by Codd et al. (1976). The illness seen in Birmingham $\overrightarrow{\vec{\sigma}}$ was, therefore, closely comparable to that seen in 3 the North-East of England in the previous year.

The syndrome of symptoms referred to as? 'epidemic neuromyasthenia', sometimes called 'be=-̄을 nign myalgic encephalomyelitis' or 'Royal Free 3 . disease', has some similarities in its presentation to the disease produced by ECHO 19. There are also. distinct differences.

The observations by the medical staff of the Royal Free Hospital (1957) and the Newcastle group (Hope Pool et al., 1961), amongst others, have led $>$ to the description of a disease entity. In a summary․ of features, Brain and Walton (1969) noted an febrile illness, with pharyngitis, upper respiratory or ${ }^{\circ}$ gastrointestinal symptoms, and lymphadenopathy, $N$ followed in a variable proportion of cases by CNS $\tilde{\omega}$ involvement. In these latter cases, emotional lability and depression, sleep disturbance, muscular weak-o ness and tenderness, cranial nerve palsies, and $\bar{\varnothing}$ sensory disturbances occurred. Electromyographic $\stackrel{?}{?}$ studies were said to be typical by a number of $\square$ observers (Medical Staff of the Royal Free Hospital, $\frac{\text { Q }}{\Phi}$ 
1957; Hope Pool et al., 1961). No aetiological agent has been described in outbreaks of the disease.

Analysis of the prodromal features of the Royal Free outbreak with those of the current ECHO 19 epidemic reveals a basic similarity, particularly in the frequency of myalgia (Table 1). The description of myalgia of the Bornholm type in both series, suggests an enterovirus aetiology which, in the case of ECHO 19, was confirmed. However, although the Royal Free patients suffered from headache and, in a third, neck stiffness, the presentation apparently did not suggest meningitis, and no lumbar puncture data were reported. This contrasts sharply with disease due to ECHO 19 (Table 2). Further, conjunctivitis and skin rashes were not reported in the Royal Free series, nor by Hope Pool et al. (1961). However, mental disturbance in 'epidemic neuromyasthenia' frequently referred to as 'hysteria' by subsequent opinion, involving dizziness, confusion, delirium and other features, are common to the series (Table 3).

The major area of dissimilarity, which refutes the argument suggesting that enteroviruses and in

TABLE 1. Comparison of prodromal features of ECHO 19 disease and those of 'epidemic neuromyasthenia'

\begin{tabular}{lcc}
\hline & $\begin{array}{c}\text { ECHO 19* } \\
(\%) \\
n=78\end{array}$ & $\begin{array}{c}\text { Royal Free outbreak } \dagger \\
(\%) \\
n=200\end{array}$ \\
\hline $\begin{array}{l}\text { Upper respiratory } \\
\text { tract infection }\end{array}$ & 52 & 64 \\
Myalgia & 40 & 47 \\
Malaise & 35 & 62 \\
Gastrointestinal & 21 & 16 \\
symptoms & & \\
\hline
\end{tabular}

- Gould et al., 1977.

† Medical Staff of the Royal Free Hospital, 1957. particular ECHO 19 may be responsible for outbreaks of 'epidemic neuromyasthenia', is the incidcnce of otjective neurological deficit present in $74 \%$ of the Royal Free patients (Table 2), again reported in $20 \%$ of the cases seen in Newcastle (Hope Pool et al., 1951) and totally lacking in the Birmingham series of aseptic meningitis due to ECHO 19. Further, although certain ECHO and Coxsackie $\checkmark$ irisses, as with poliovirus, have been associated vith motcr paralysis (Ranzenhofer et al., 1958; M:Allister, 1960), the paralysis produced tends to be of the ascending type and does not involve sensory change.

TABLE 2. Comparison of major clinical features of ECHO 19 disease and those of 'epidemic neuromyasthenia'

\begin{tabular}{lcc}
\hline & $\begin{array}{c}\text { ECHO 19* } \\
(\%) \\
n=78\end{array}$ & $\begin{array}{c}\text { Royal Free outbreak } \dagger \\
(\%) \\
n=200\end{array}$ \\
\hline Headache & 100 & 77 \\
Neck stiffness & 90 & 33 \\
Photophobia & 82 & -12 \\
Vomiting & 67 & 89 \\
Fever & 53 & 47 \\
Myalgia & 44 & - \\
Conjunctivitis & 22 & $2-3$ weeks \\
Duration & 1 week & (occasionally, \\
& & 1-3 months) \\
\hline
\end{tabular}

- Gould et al., 1977.

$\dagger$ Medical Staff of the Royal Free Hospital, 1957.

It therefore appears unlikely that the fully developed disease due to ECHO 19 can be compared with 'epidemic neuromyasthenia'. However, the vast majority of cases of disease, presumptively due to this virus, did not present to hospital, having milder disease of the type noted in the family contact study described above and by general practitioners.

TABLE 3. Comparison of neurological features of ECHO 19 disease and those of 'epidemic neuromyasthenia'

\begin{tabular}{|c|c|c|}
\hline & $\underset{n=78}{\operatorname{ECHO~} 19 *(\%)}$ & $\begin{array}{l}\text { Royal Free outbreak } \dagger(\%) \\
\qquad n=200\end{array}$ \\
\hline \multicolumn{3}{|l|}{ Non-specific features: } \\
\hline $\begin{array}{l}\text { Dizziness } \\
\text { Confusional state }\end{array}$ & $\begin{array}{l}44 \text { (vertigo, rare) } \\
13\end{array}$ & $\begin{array}{l}34 \text { (vertigo, common) } \\
\text { Common: emotional lability' } \\
\text { and 'hysteria' }\end{array}$ \\
\hline \multirow[t]{3}{*}{ Specific signs: } & Not observed & $\begin{array}{l}74 \text { (148 patients) } \\
\text { Cranial nerve palsy } 46\end{array}$ \\
\hline & & Bulbar palsy \\
\hline & & $\left.\begin{array}{l}\text { Motor signs: } \\
\text { weakness, } \\
\text { fasciculation, } \\
\text { myoclonus. }\end{array}\right\} \begin{array}{l}\text { almost } \\
\text { invariably }\end{array}$ \\
\hline
\end{tabular}

* Gould et al., 1977.

† Medical Staff of the Royal Free Hospital, 1957. 
Hope Pool et al. (1961) suggested that the disease should be considered in patients with a relapsing illness associated with muscular weakness and emotional disturbance. This description covers a wide range of possibilities, factual, functional or fictional. Although the cases of disease due to ECHO 19 in the community might be broadly described by this description, the fully developed diseases only must be compared, and on this basis the disease epidemic in the North-East in 1974 and in the West Midlands in 1975 was not 'epidemic neuromyasthenia'.

\section{References}

Brain, LORD \& WALTON, J.N. (1969) Benign myalgic encephalomyelitis. In: Diseases of the Nervous System. 7th Editn. London, New York \& Toronto, Oxford University Press.
Codd, A.A., Hale, J.H., Bell, T.M., Sims, D.G., Bacon, C.J. \& GARDNER, P.S. (1976) Epidemic of echovirus 19 in the north-east of England. Journal of Hygiene. Cambridge, 76, 307.

Gould, I., Clarke, P.D., Ball, A.P., Campbell, A.D., HADley, R.E. \& GedDes, A.M. (1977) An outbreak of meningitis caused by echovirus type 19. Practitioner 218, 371.

Hope Pool, J., Walton, J.N., Brewis, E.G., Uldall, P.R., Wright, A.E. \& GARDNer, P.S. (1961) Benign myalgic encephalomyelitis in Newcastle upon Tyne. Lancet, $\mathbf{i}, 733$.

Leading Article (1975) Echo virus 19 this summer? British Medical Journal, 2, 346.

MCAllister, R.M. (1960) ECHO virus infections. Paediatric Clinics of North America, 7, 927.

Medical Staff of the Royal Free Hospital (1957) An outbreak of encephalomyelitis in the Royal Free Hospital, Group, London, 1955. British Medical Journal, 2, 895.

RANZENHOFER, E.R., Dixon, F.C., LiPTON, M.M. \& Steigman, A.J. (1958) Clinical parlaytic poliomyelitis due of to Coxsackie virus group A type 7. New England Medical Journal, 259, 182.

\section{Discussion}

Chairman: Dr Ball has made the comparison between echovirus meningitis and "Royal Free disease" very well. I was particularly impressed by the factor of myalgia.

DR A. T. RoDEN (London): I should like to ask Dr Ball one short question on one of his slides which puzzled me. It showed a comparison of the clinical features of echovirus type 19 infection and 'epidemic neuromyasthenia'. If my memory is right, it showed against 'fever' $53 \%$ under echovirus and a somewhat higher percentage under 'epidemic neuromyasthenia'. I wondered if he regarded this as a usual feature in echovirus infection, because my impression was that the ratio should be reversed in these two conditions.

DR A. P. BALl: Our patients were, of course nou admitted precisely at the onset of their illness. Fever is common feature of enterovirus illnesses. By the time patients come into hospital, they may have had their major illness type of features for two or three days and are frequently afebrile, as was the case in our study. 